\title{
El ruidoso cuerpo de Frida: una lectura fenomenológica sobre la obra de Frida Kahlo*
}

\author{
The noisy body of Frida: a phenomenological reading about the work of Frida Kahlo
}

O corpo barulhento de Frida: uma leitura fenomenológica sobre a obra de Frida Kahlo

\begin{abstract}
Abel Guerrero**
Universidad del Rosario, Universidad de los Andes, Bogotá, Colombia

Correo electrónico: amguerrero1022@gmail.com

Revista Corpo-grafías: Estudios críticos de y desde los cuerpos / Volumen 5 - Número 5 / Enero - diciembre de 2018 / ISSN impreso 2390-0288, ISSN digital 2590-9398 / Bogotá, D.C., Colombia / pp. 174-191.

Fecha de recepción: 10 de julio de 2017

Fecha de aceptación: 30 de julio de 2017

Doi: https://doi.org/10.14483/25909398.14215

Cómo citar este artículo: Guerrero, A. (2018, enero-diciembre). El ruidoso cuerpo de Frida: una lectura fenomenológica sobre la obra de Frida Kahlo. Revista Corpo-grafías: Estudios críticos de y desde los cuerpos, 5(5), p-p 174-191/ ISSN 2390-0288.

*Artículo de investigación: Es el resultado de un ejercicio analítico que el autor se ha planteado en el marco de una investigación en curso, la cual busca analizar ciertos aspectos fenomenológicos observados en estrategias de arteterapia implementadas en la institución de salud con la cual trabaja actualmente.

**Médico de la Universidad del Rosario, Especialista en Psiquiatría y Salud Mental de la Universidad del Rosario, Bogotá. Psicoterapeuta cognitivo-conductual del Beck Institute, Philadelphia, Magíster en Antropología de la Universidad de los Andes. Psiquiatra y psicoterapeuta en la Unidad de Salud Mental del Hospital Santa Clara (Subred de Servicios en Salud - Centro Oriente, Bogotá), y referente de Salud Mental de la Dirección de Provisión de Servicios de la Secretaría Distrital de Salud. Miembro investigador de la Red de Etnopsiquiatría: Estudios sociales y de la cultura de la Universidad de los Andes.
\end{abstract}

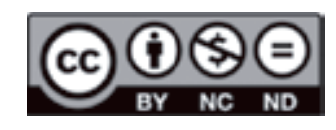




\section{Resumen}

El presente artículo ofrece una lectura de la obra de Frida Kahlo desde la psiquiatría y la fenomenología. En este sentido, desarrollo algunas consideraciones sobre sus particulares condiciones médicas, para posteriormente presentar una hipótesis sobre la presencia de experiencias autoscópicas ${ }^{1}$ como una probable causa de su "necesidad" de dibujarse, esto mediante un análisis fenomenológico ${ }^{2}$ del material experiencial dejado por ella: entrevistas y diario personal.

Palabras clave: fenomenología; fenómenos autoscópicos; Frida Kahlo.

\section{Abstract}

The present article offers a reading of Frida Kahlo's work from a psychiatric and phenomenological perspectives. In order to achieve this, I make some considerations about her particular medical conditions and offer a hypothesis about the presence of autoscopic experiences as a probable source of her "need" to draw herself, all this through a phenomenological analysis of the experiential material left by her: Interviews and diary.

Keywords: phenomenology; autoscopic phenomena; Frida Kahlo.

\section{Resumo}

Este artigo oferece uma leitura do trabalho de Frida Kahlo da psiquiatria e fenomenologia. Nesse sentido, desenvolvo algumas considerações sobre suas condições médicas particulares, para posteriormente apresentar uma hipótese sobre a presença de experiências autoscópicas como causa provável de sua "necessidade" de desenhar, através de uma análise fenomenológica do material experiencial deixado por ela: entrevistas e Diário.

Palavras-chave: fenomenología; fenômenos autoscópicos; Frida Kahlo.

1 Alucinaciones del self. Estos conceptos se desarrollarán más adelante

2 La fenomenología es un método de análisis filosófico fundado por el matemático (y posteriormente filósofo) Edmund Husserl. Busca la descripción rigurosa de la experiencia consciente mediante un ejercicio de 'entrecorchamiento' (bracketing) o 'suspensión' de la experiencia. Busca develar, resumiéndolo de manera muy concreta, la experiencia consciente en sí misma. 


\section{Introducción}

Magdalena del Carmen Frida Kahlo Calderón. Al oír su nombre lo primero que evocamos es su rostro; o mejor, alguno de sus autorretratos. No creo que exista un artista cuya obra-para el imaginario lego y experto- se asocie casi que exclusivamente con las pinturas que de sí misma hizo. No es de extrañar que esto sea así, pues cerca de 70 de sus 143 pinturas fueron autorretratos, y sin duda corresponden en su mayoría a lo más reconocido de su obra (Dosamantes, 2001; Donahue, 2011). Esta situación resulta muy llamativa: ¿qué facilita que un artista limite, hasta cierto punto, el grueso de su producto creativo a una serie de autorretratos? Ciertamente Frida intentó contestar esta pregunta con su anecdótico "me retrato a mí misma porque estoy mucho tiempo sola... Me pinto a mí misma porque soy a quien mejor conozco" (Garrido, 2014), pero considero necesario explorar con mayor profundidad las situaciones que pudieron facilitar este hecho.

Es mucho lo que se ha dicho al respecto de los autorretratos de Frida Kahlo (FK), pudiendo encontrarse modelos psicoanalíticos, neurológicos, estéticos, socioculturales entre otros, que aventuran alguna hipótesis tanto de los motivos como de las interpretaciones 'inconscientes' de su obra. El presente escrito no pretende nada diferente que aventurar una lectura más de la obra de esta extraordinaria artista mexicana, pero en esta ocasión desde un lente neuropsiquiátrico fenomenológicamente situado como propuesta de acercamiento a las experiencias del proceso creativo de Frida Kahlo.

No es sencillo intentar explorar las experiencias de alguien a quien no tendremos oportunidad de entrevistar; sin mencionar que Frida dejó poco material escrito que diera cuenta de su subjetividad o experiencia del mundo. No obstante, Frida dejó un gran legado artístico del que, como refiere Carlos Fuentes (1995), es posible leer una biografía que podría acercarnos a su experiencia íntima.

Por obvias razones, las fuentes principales de este escrito fueron su obra y su propio diario (Kahlo, 1995). Sobre este último, debo aclarar que no se trata de un texto que dé cuenta sincrónica de lo sucedido en un día particular. Más bien, se trata de un documento con una intencionalidad comunicativa particular, más íntima y personal que intersubjetiva. No obstante, todo lo allí plasmado fueron ejecuciones espontáneas que ofrecen, sin duda, una ventana a su experiencia. Frida volvía, como es sabido, sobre sus textos y bosquejos, en una continua edición-re edición, sin que hubiese linealidad temporal clara en este ejercicio. Frida, como ella misma lo dice en su diario, nos escribe "con los ojos" en este, su autorretrato más íntimo.

\section{El cuerpo roto}

El impacto del dolor y la enfermedad en la vida y obra de Frida es innegable. En otras palabras, Frida hizo de su cuerpo adolorido el objeto de su obra. Una buena parte de su creación retrató su sufrimiento a través de su cuerpo herido y sangrante; y de estas circunstancias, curiosamente, muchas tenían una base neurológica. Siguiendo a Budrys (2006), una buena parte de los problemas médicos presentados por Frida aparecen probablemente antes de su nacimiento, sugiriendo que la artista nació con un defecto congénito llamado Espina Bífida, una anomalía de la columna vertebral que se caracteriza por la falta de fusión o fusión incompleta de las láminas de los arcos espinales (Imagen 1). 


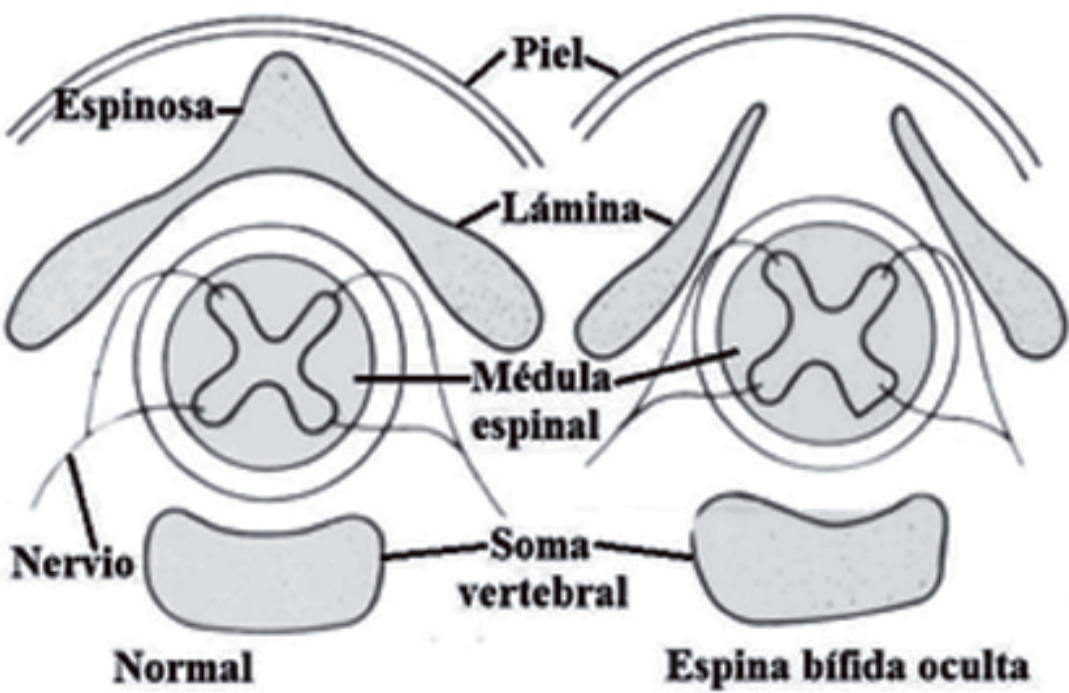

Imagen 1. Tomada de: http:// neuros.net/es/espina_bifida/

Estas anormalidades corresponden a un defecto del cierre del tubo neural (sustrato embrionario del cual se desarrolla todo lo relacionado con el sistema nervioso central: cerebro, médula espinal, meninges, cráneo, vértebras) durante las primeras 4 semanas del desarrollo embrionario (Kauffman, 2013). Dependiendo de la severidad de la malformación, el cuadro puede ser asintomático o cursar con manifestaciones musculoesqueléticas, urológicas o neurológicas diversas (Kaufman, 2013).

Citando a Sandblom (1999), Budrys (2006) confirma la presencia de esta malformación en un documento del cirujano y amigo de Frida, Leo Eloesser, en el que asocia alteraciones en la sensibilidad de las extremidades inferiores de la artista con el hallazgo incidental de la espina bífida en unos rayos $X$ realizados.

Sin otro documento médico que pueda confirmar este hallazgo, Budrys (2006) apela al detallado defecto del pie izquierdo en 'Lo que el agua me dio' (Imagen 2). Allí, uno de los elementos dominantes del cuadro son el par de pies asomados por encima del nivel del agua de la bañera, donde la herida sangrante entre unos deformes primer y segundo dedo del pie derecho parecen dominar la escena. Se trata de un defecto que frecuentemente acompaña trastornos del desarrollo del tubo neural, incluyendo la espina bífida (Kaufman, 2013). Es entendible que en ese momento se hubiese pasado por alto este defecto, pero como propone Budrys (2006), es poco probable que el cuadro de poliomielitis explicase por si solo la deformidad en la pierna de Frida. Es más probable que dicha enfermedad haya potenciado los defectos congénitos de su pierna derecha, haciéndolos más notables durante su crecimiento, sugiriendo que las alteraciones de esta pierna son mejor explicadas por la sumatoria de efectos de ambas enfermedades (Budrys, 2006).

A los 18 años, Frida sobrevivió al accidente sufrido en el choque del 'camión' en que viajaba. De aquí se derivaron múltiples lesiones: columna vertebral, pelvis, útero, así como pie y pierna derechos; en consecuencia debió permanecer en cama por largos periodos. A pesar de su aparente recuperación, Frida presentó dolores cada vez más intensos y frecuentes que obligaron la práctica de nuevos exámenes, incluidos aquí unos rayos $X$ de columna que documentaron la fractura de algunos cuerpos vertebrales que, aparentemente, habían sido pasados por alto (Budrys, 2006). 
Imagen 2. Lo que el agua me dio, 1939. Óleo sobre tela, $69 \times 88 \mathrm{cms}$

Tomada de: https:// demasiadoelemental.files. wordpress.com/2016/01/ lo-que-vi-en-el-agua-obrade-frida.jpg

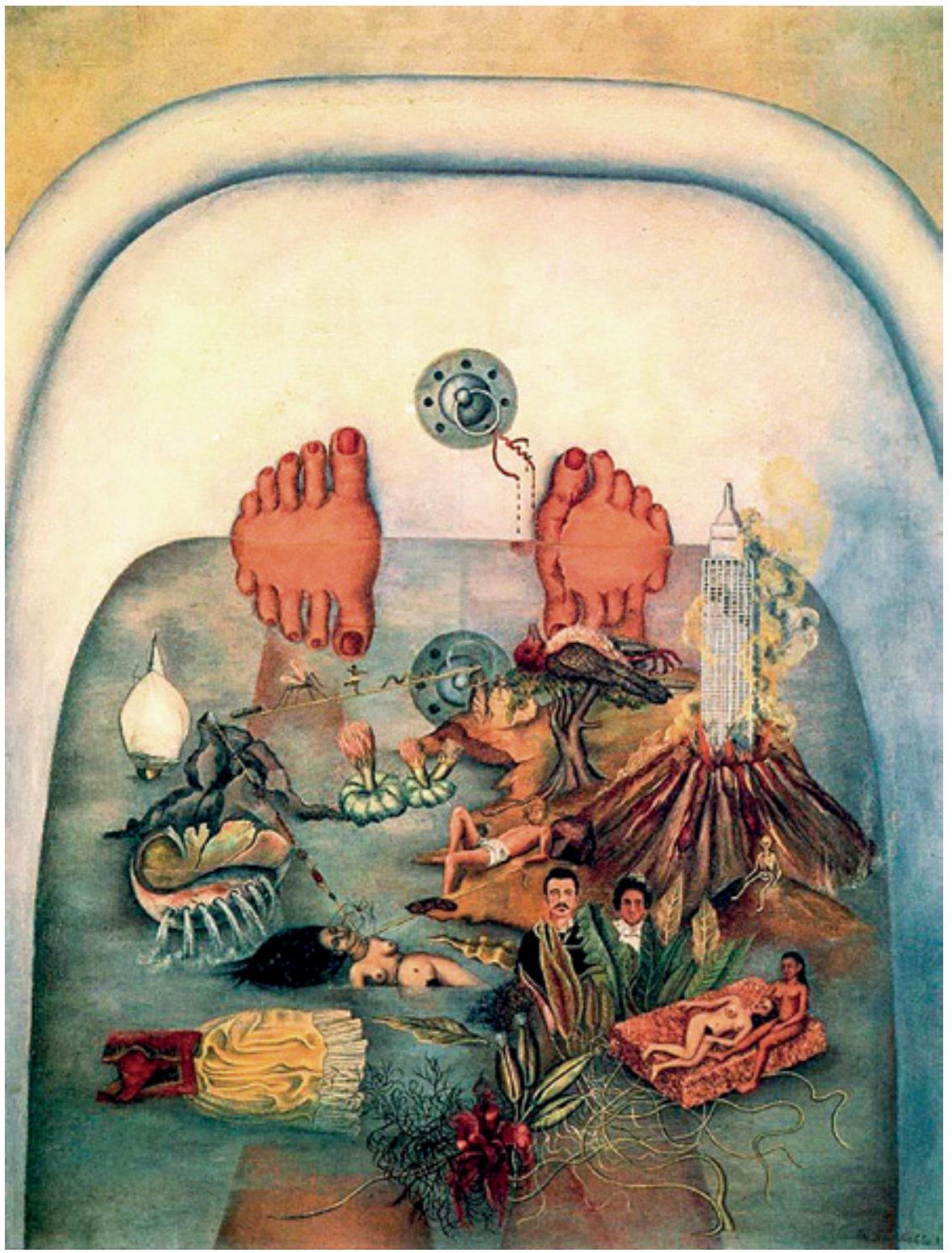

Durante varios meses Frida permaneció en el hospital usando corsets ortopédicos que limitaban su movilidad. Fue en este contexto que solicitó a su padre un juego de pintura: "Sentí que tenía energía suficiente para hacer algo diferente que estudiar [...]. Sin pensarlo demasiado, empecé a pintar" (Kettenmann, 2003). Sus padres encargaron la construcción de un caballete especial para que pudiese dibujar estando en cama; y fue así como empezó a dibujar como un medio para lidiar con sus largos periodos en cama y soledad (Imagen 3). 


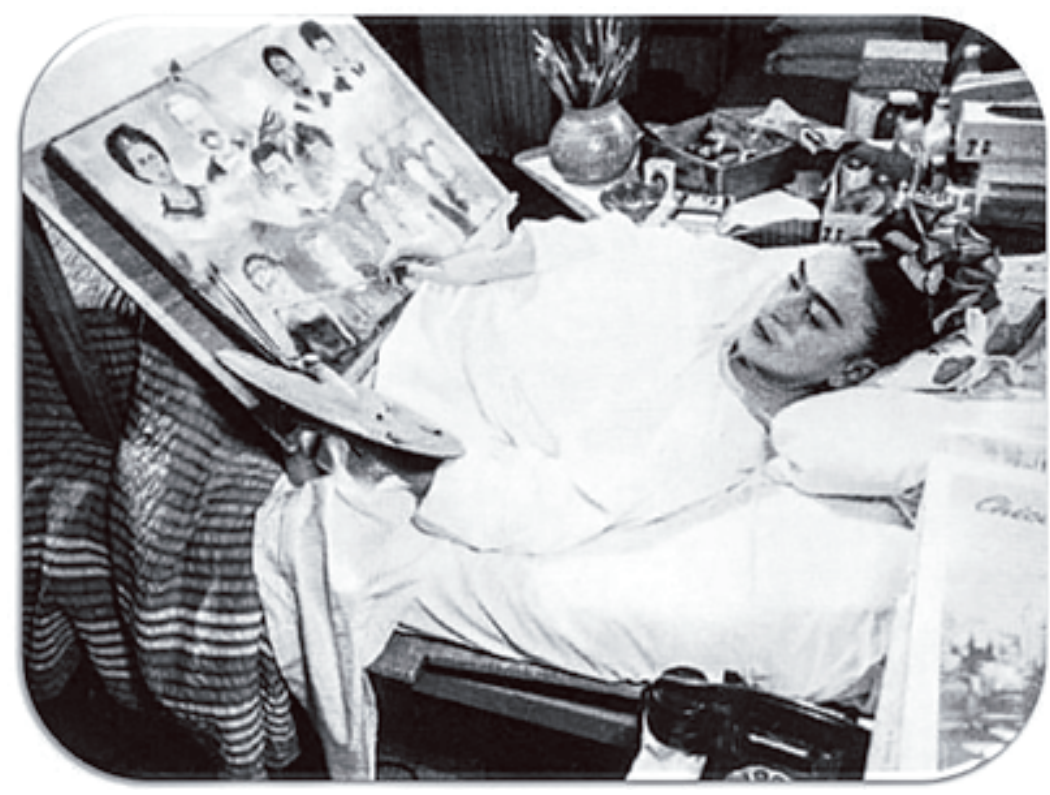

Imagen 3. Foto de Juan Guzmán, 1952. Consultada en mayo de 2017 en: http:// fotografica.mx/juanguzman/foto-jg/jgcdmx-40/

Si bien no hay certeza sobre cómo o cuándo los espejos se convierten en los inseparables compañeros de Frida, lo cierto es que delimitaron una suerte de marco en el que podríamos explicar su necesidad de pintarse. Según Inés Ruiz (2007) Matilde, madre de Frida, ideó el mecanismo para colgar un espejo sobre la cama de Frida, facilitando que su cuerpo se convirtiese en el modelo de su obra. Más adelante volveré sobre la relevancia de esto en el desarrollo de su obra.

Entre 1946 y 1951, Frida fue sometida a varios procedimientos quirúrgicos ${ }^{3}$, tras los cuales terminó confinada al uso de una silla de ruedas la mayor parte del tiempo, así como al uso regular de analgésicos como consecuencia del dolor neuropático (Budrys, 2006) que la acompañó. Este punto es de vital importancia en el argumento que pretendo desarrollar. El dolor, como cualquier fenómeno mental, es un suceso subjetivo que sucede en una mente encarnada, automático en el psiquismo de quien lo padece y no requiere de ningún tipo de reflexión cognitiva para su experiencia y reconocimiento (Guerrero, 2012). Si bien tenemos una idea clara de a qué me refiero aquí con la palabra dolor, es claro también lo difícil que resulta explicar qué es: solemos describirlo bajo términos del orden "es como si...", aludiendo a experiencias particulares -que por cierto, es poco probable las hayamos experimentado- (i.e. es como si me quemara con un hierro caliente, es como si me enterraran un alfiler frío, es como si me apretaran con una prensa, etc.); podemos describir algunas de sus características como intensidad (fuerte, suave), ubicación (dedo, muela), temporalidad entre otras características (constante, recurrente, intermitente), pero explicar qué es resulta una empresa casi imposible con los recursos lingüísticos con los que contamos usualmente. Las sensaciones dolorosas suelen originarse por la estimulación nociceptiva (estimulación de receptores nerviosos del dolor) sufrida en el cuerpo por alguna lesión. Independientemente a su etiología (causa), el dolor crónico que acompañó a Frida en su miembro inferior derecho como consecuencia de las lesiones recurrentes en su pie, infecciones y ulceraciones (que culminaron con la aparición de gangrena que requirió su amputación en 1953), así como los dolores de espalda posterior a las lesiones sufridas durante el accidente, fueron situaciones que sin duda merecieron su atención. Un claro ejemplo de ello fue la pintura realizada en su diario (Imagen 4), en la que se observa un par de pies, desde los que salen una suerte de rayos o espinas que me hacen recordar comentarios de pacientes con dolor neuropático con los que he tenido la oportunidad de hablar: "son como corrientazos... latigazos de dolor"4 .

339 en total a partir de los 18 años (Herrera, 1983).

4 Antiguo Diario de campo personal del autor, anotación fechada marzo 27 de 2010. 
Imagen. 4. Pies para qué los quiero, si tengo alas para volar. 1953. Foto del facsímil del Diario de Frida Kahlo, 1995. Jorge Guerrero.

Sobre decir aquí que este diagrama (Imagen 4) no fue la única descripción simbólica del dolor en sus pinturas; al respecto su obra está plagada de ejemplos: clavos, flechas, heridas sangrantes, lágrimas; todos hacen parte del espectro de símbolos mediante los cuales aludió al dolor como parte de su vida. Resumiendo, Frida fue una artista cuyo talento pareciera surgir como un medio para lidiar con el sufrimiento físico y emocional que la acompañaron desde temprana edad y hasta su muerte en julio de 1954.

\section{Cuerpos silentes}

Como sugiere Phillip Zarilli (2004) la filosofía Occidental, desde el siglo XVII, relegó el estudio de lo corporal a análisis mecanicistas, al mismo nivel que el estudio de otros objetos materiales. No fue sino hasta mediados del siglo 20 que pensadores como Heidegger o Merleau-Ponty propusieron un nuevo paradigma en el análisis de lo corporal como sustrato indispensable de la experiencia subjetiva humana. Rechazando las entonces posturas vigentes de las ciencias naturales y la psicología moderna que entendían

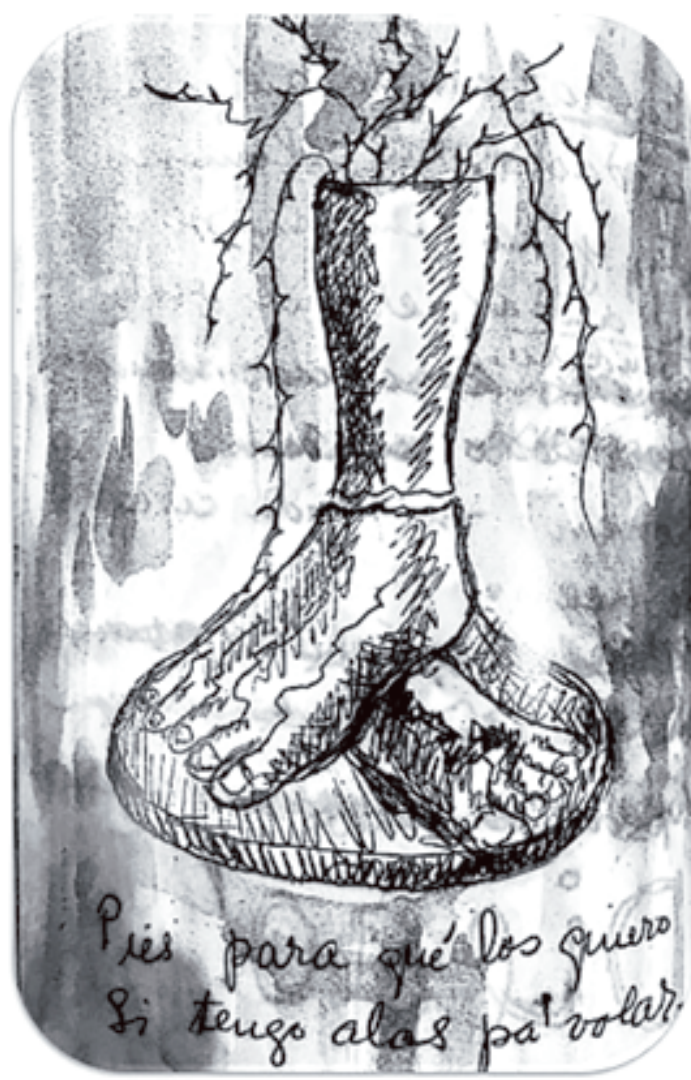
el cuerpo como una suerte de elemento mecánico (körper), como una máquina bajo el control de una mente autoconsciente, la filosofía pone en la escena central la necesidad de reconocer el cuerpo como un cuerpo vivo $(l e i b)^{5}$, base de una experiencia encarnada (embodied) como medio de la interacción con el mundo. Esto, siguiendo a Thomas Fuchs (2005), no nos deja más remedio que aceptar que nuestra subjetividad está inmersa (embedded) en el mundo, volviendo este cuerpo vivo el mediador de esa experiencia: "La conciencia, como la luminosidad que revela el mundo al sujeto, es el resultado de esa mediación" (Fuchs, 2005, p. 95). Lo sorprendente aquí es que este cuerpo, innegable medio de nuestras experiencias del mundo y origen de nuestra subjetividad (encarnada), es absolutamente translúcido, o insonoro, para la mayoría de nosotros. El cuerpo es el medio por el cual percibimos -e interactuamos con- el mundo. Drew Leder (1990) (Citado en Zarilli, 2004, p. 656.) señala al respecto:

"Aunque nuestro cuerpo es la presencia más duradera e inescapable de nuestras vidas, está esencialmente caracterizado por su ausencia. Es decir, nuestro cuerpo es raramente el objeto temático de nuestra experiencia. Cuando leemos un libro o nos encontramos absortos en nuestros pensamientos, mis propios estados corporales parecen ser la cosa más lejana de mi conciencia. Yo, experiencialmente, resido en un mundo de ideas, prestando poca atención a mis sensaciones físicas o postura". (Traducción libre)

5 Körper alude al cuerpo mecánico, traduciéndose frecuentemente como cadáver o cuerpo muerto. Leib, por su parte designa un cuerpo vivo. Siguiendo a Fierro (2013), del ámbito del Körper sería la articulación del codo como una bisagra y los nervios como un cableado eléctrico; mientras que del ámbito del Leib sería el cuerpo sentido como obeso de una anoréxica o el cuerpo sentido como hueco por dentro en un delirio nihilista. 
El proceso constitutivo inherente a nuestra experiencia consciente es normalmente inconsciente; es decir, es un proceso implícitamente presente en nuestra relación con el mundo, generando esa transparencia (en el marco de la experiencia subjetiva) que caracteriza nuestro cuerpo (Fuchs, 2005). Esta translucidez o silencio corporal no se limita a los momentos de abstracción autocontemplativa (por decirlo de alguna forma), sino que es la actitud o disposición característica de la experiencia subjetiva cotidiana.

Esta manera, mediante la cual experimentamos el mundo, es la que nos permite actuar en pro de nuestras metas como agentes autónomos. Desafortunadamente, esto no es tan cierto para todos. En personas con alteraciones neurosensoriales o deficiencias sensoriomotoras (como en el caso de parálisis en partes del cuerpo), incluso en algunos trastornos mentales, este silencio o translucidez de lo corporal se ve alterada por la interrupción de esa fluidez en nuestra interacción con el mundo. Es como si el cuerpo adquiriera su materialidad, convirtiéndose en un obstáculo, en vez de un medio, para nuestra interacción con el mundo (Fuchs, 2005). Este es también el caso de personas que padecen de cuadros de dolor crónico (Zarilli, 2004).

Existe otra familia de experiencias en las que se pierde, de igual forma, esa unidad subjetiva encarnada (mente encarnada) característica de nuestra experiencia, resultando en lo que podría llamarse experiencias de "mente des-corporalizada" (disembodied mind) (Fuchs, 2005), dando origen a lo que, en psiquiatría y ciencias cognitivas, se denominan alucinaciones autoscópicas (Mishara 2010a, 2010b). Los fenómenos o alucinaciones autoscópicas (del griego 'verse a sí mismo') comprenden una variedad de experiencias en las que el sujeto ve (o tiene la profunda sensación de experimentar en la cercanía) un doble externo a su propio punto de vista o experiencia (Mishara, 2010a). Si bien es cierto que en nuestra experiencia cotidiana el cuerpo y el self o Yo narrativo de nuestra experiencia subjetiva son usualmente vivenciados de manera conjunta, desde la fenomenología y las ciencias cognitivas se ha propuesto que no se trata de un fenómeno tan monolítico como inicialmente se pensó (Johnson ,2008; Gallagher 2005) ${ }^{6}$.

Las alucinaciones autoscópicas suelen clasificarse en 4 tipos (Mishara 2010 a): Autoscopía de espejo o tipo 1 (el sujeto ve la imagen de su cuerpo como en un espejo. Si bien la experiencia es descrita como perturbadora, el sujeto reconoce su mismidad en el agente que ve la alucinación, es decir, 'yo veo una imagen especular de mí mismo'); Autoscopía delirante o tipo 2 (en este tipo, la intensidad de la imagen no es tan nítida como en la anterior, pero la experiencia si resulta más perturbadora ya que la imagen alucinada, pareciera 'robar el self', como si de una 'mismidad' compartida se tratara); Experiencias Extra-corporales, (Out of Body Experiences -OBE-) o tipo 3 (como su nombre lo dice, se trata de un fenómeno en el que el sujeto tiene la sensación de 'salirse del cuerpo' y lo observa [su cuerpo] desde una posición elevada) y Sensación de presencia (feelings of presence, FOP) o tipo 4 (es la sensación de una presencia cercana, mas no hay visualización del fenómeno. El sujeto puede incluso decir en qué dirección o distancia aproximada siente dicha presencia). Se trata, en general, de experiencias poco frecuentes y pueden durar entre segundos y tiempos más prolongados (horas o meses) de manera constante o intermitente (Sadock, Ruiz, 2015).

La etiología de estos fenómenos alucinatorios es muy variada (Mishara, 2010 a). Se presentan en casos en los que se confirma la presencia de lesiones neurofisiológicas o neuroanatómicas diversas (epilepsias, tumores, intoxicación por sustancias psicoactivas, entre otras), así como en cuadros mentales primarios -es decir, sin causas orgánicas- como depresión o esquizofrenia. Igualmente se pueden presentar en sujetos 'sanos' como parte de un tipo de alucinaciones propias de los periodos de sueño (hipnagógicas o del inicio del sueño, e hipnopómpicas, o del final del sueño o despertar. El ejemplo típico de este tipo de alucinaciones es la experiencia de sentir que nos

6 Por cuestiones de espacio, es imposible llevar a cabo una discusión que pueda dar cuenta de los aspectos fenomenológicos implicados en este tipo de experiencias. Sin embargo, para el lector interesado, sugiero acercarse a los trabajos de Johnson (2008) y Gallagher (2005) cuyos aportes sobre conceptos como la imagen y esquema corporal apuntan a ser un sustrato explicativo de este tipo de fenómenos. 
estamos cayendo mientras nos quedamos dormidos). De igual manera han sido descritas en sujetos proclives a fantasear mucho en su cotidianidad, por lo que no es extraño oír sobre artistas que hacen alusión a este tipo de experiencias (Mishara, 2010 b).

La translucidez o silencio de lo corporal implica que la conciencia no es el resultado final de una serie de procesos mecánicos de un cuerpo. La mente, o lo mental, no es un fenómeno puro o etéreo en el que yace la subjetividad. Todo lo contrario. La mente es la integración de una serie de procesos que tienen su base en el cuerpo vivo que somos. Esta conciencia encarnada (mente) es a la vez un cuerpo que actúa como medio, a través del cual percibimos e interactuamos con el mundo; pero el actuar de este cuerpo es implícito, y el proceso inherente a la constitución de nuestra experiencia consciente escapa a su observación.

Siguiendo lo propuesto por Fuchs (2005), la transparencia de lo corporal encuentra su nicho en una estructura del tipo 'como si', en donde experimentamos la afectación del mundo en nosotros (percepción sensorial) como si fuesen los objetos que percibimos o sobre los que actuamos. Con base en lo propuesto por Leder (1990), Fuchs (2005) sugiere que, como medio de la experiencia consciente, el cuerpo se repliega en la "dimensión de lo tácito", escondiéndose en el acto mismo de revelar lo observado; lo que se experimenta. Así, el silencio de lo corporal, surge de la naturaleza encarnada de la mente.

Estoy convencido que Frida perdió esa cualidad silente de su corporalidad, y veo esto factible por dos circunstancias particulares: primero el dolor que, como decía, fue su fiel compañero. Segundo, y necesariamente ligada con la anterior, alguna suerte de fenómeno hiperreflexivo ${ }^{7}$ emergente de sus largas jornadas de soledad frente al espejo. En conjunto, y esta es mi apuesta aquí, generaron en ella la capacidad de experimentarse no solo en primera persona, sino incluso en tercera persona, como una observadora externa de sí misma, llegando en algún momento a generar una franca experiencia alucinatoria autoscópica.

\section{El doloroso cuerpo de Frida}

El dolor, sin lugar a dudas, acompañó constantemente a Frida, siendo la experiencia más constantemente plasmada en su obra:

"iDios mío! Decir que el dolor echa raíces en mí. En mi crece. Grita. Cerebro, ¿hasta qué punto controlas toda esa distorsión? Vida mía, ¿cuál es tu parte de responsabilidad? A veces, dudé de que la polio o el accidente hubiesen existido realmente, pensé que mi cuerpo lo inventó todo, que nació con él, se desbarató sólo por un oscuro deseo de destrucción"-(Rauda, 2003, p.253).

Para Frida, el dolor pareciera ser una experiencia corporal integrada, amplia: "No puedes imaginarte el dolor que siento, cada movimiento desencadena litros de lágrimas" (Ibidem, p. 96). Para resaltar la importancia de este punto quiero pedir al lector que recuerde la última vez que pensó en, por ejemplo, sus intestinos. Realmente no tenemos una imagen mental fluida o permanente de esa parte de nuestro cuerpo. Su funcionamiento escapa a nuestra conciencia cotidianamente; sin embargo, sabemos que existen sin la menor duda cuando tenemos dolor. El dolor los pone irremediablemente en nuestra conciencia. Pierden su transparencia cotidiana en el mundo de sensaciones subjetivas que somos. Ahora intentemos realizar el ejercicio mental de extrapolar esto a la presencia de un cuerpo constantemente adolorido; no es difícil imaginarnos lo masiva que podría resultar, para el psiquismo, una situación así. El cuerpo se vuelve objeto de su propia experiencia álgico dificultando la experiencia cotidiana tal y como se nos presenta a la mayoría de personas. Pienso es a esto a lo que se refiere Frida cuando afirma que:

7 Hiperreflexividad deberá entenderse como una forma exagerada de auto-conciencia (Sass, 2013). Si bien para Sass y Parnas esta hiperreflexividad es un fenómeno más 'primario' y experiencial, aquí deberá asumirse como un fenómeno más metacognitivo, más del pensamiento que de la experiencia 'primaria' sugerida por esos autores. Agradezco la opinión del profesor Marco Fierro a propósito de esta acepción. 
“Cada día soy más torpe. Lo tiro todo. Todo el día voy llena de manchas de pintura... Como si ya no supiese pintar [...] Ya no me aguanto más a mí misma... Ya no soporto nada. [...] Y nunca ha habido un tiempo para estar bien, ni tiempo para ver los templos mayas del Yucatán, ni tiempo para ver las maravillas de Florencia. Mi cuerpo se ha atravesado siempre en mi camino" (énfasis mío) - (Rauda, 2003, p. 289).

No creo que pueda explicarse mejor: Su cuerpo se convirtió en una talanquera para vivir. Su cuerpo pareciera haber adquirido una dolorosa materialidad que le impide una interacción más fluida con el mundo. El dolor captura su atención de manera recurrente. Su cuerpo, a través del dolor, ha perdido la silente cualidad que caracteriza la experiencia subjetiva cotidiana. Esto, considero, fue una situación de relevancia mayúscula en el proceso por el cual Frida terminó casi que compelida a dibujarse.

\section{Frida a través del espejo}

Tras sufrir el accidente del tranvía, a la edad de 18 años, Frida se vio obligada a permanecer largas temporadas en soledad frente al espejo. No es de extrañar entonces que la artista empezara a desarrollar una particular manera de relacionarse con su imagen:

"iEl espejo! Verdugo de mis días, de mis noches. Imagen tan traumatizante como mis propios traumas. La impresión constante de que te señalan con el dedo. 'Frida, mira. Frida, mírate pues'. Ya no hay una sombra verdadera dónde esconderse, una guarida segura dónde retirarse, abandonada al dolor, para llorar en silencio sin marcas en la piel. [...] Escrutaba mi cara, el menor gesto, los dobleces de la sábana, su relieve, las perspectivas de los objetos esparcidos que me rodeaban. Durante horas me sentía observada. Me veía. Frida dentro, Frida fuera, Frida en todas partes, Frida hasta el infinito"- (Rauda, 2003, p. 107)

Quisiera llamar su atención aquí es sobre las sugerentes palabras de Frida: "Me veía. Frida dentro, Frida fuera, Frida en todas partes". Según Helmut Plessner (1981) (citado y traducido en Fuchs 2005) ese Yo encarnado que somos mantiene una relación ambivalente con su ambiente, y señala que esta ambivalencia está basada en lo que denomina una capacidad de posicionamiento excéntrico. A lo que hace referencia Plessner es a la oscilación continua de nuestra conciencia entre la experiencia subjetiva (de estar dentro del cuerpo de uno) y la experiencia del mundo (estar con lo que sucede fuera, en el mundo). A lo que alude esta capacidad es a la oscilación del foco de atención cotidiano cuando, por ejemplo, vamos por la calle con audífonos puestos. Cuando vamos caminando, si bien es cierto que vamos navegando por el espacio de forma suficientemente hábil, podríamos decir que la experiencia global es de estar en nuestro cuento, vamos oyendo alguna canción y la experimentamos con cierto tono emocional. Es una experiencia interna, subjetiva. No obstante, si algún estímulo ambiental resulta suficientemente llamativo, nuestra atención se desviará a ese estímulo, lo evaluaremos y definiremos su relevancia con respecto a nosotros mismos. Es en este caso que nuestra conciencia está puesta afuera, para rápidamente volver al entorno de lo subjetivo ${ }^{8}$.

Considero que de alguna manera intuitiva Frida empezó a hacer cada vez más consciente esta capacidad de posicionarse extrínsecamente a través de su diario ejercicio autocontemplativo frente al espejo:

8 Es indispensable aclarar aquí que estos fenómenos se suceden de manera conjunta (podría decir) por lo que este tipo de descripciones a veces resultan poco intuitivas a la experiencia cotidiana. De esta manera, espero que el lector comprenda que al ponerlas aquí como fenómenos diferentes es más con fines didácticos que como descripciones de la experiencia subjetiva tal y como se nos presenta. 
"A la manera clásica, para aprender utilicé un modelo: yo. No era fácil, es igual que tú seas el tema más evidente, también para uno mismo es el más difícil. Crees conocer cada fracción de tu cara, cada rasgo, cada expresión, pero todo cambia sin cesar. Uno es uno y otro, creemos conocernos hasta la punta de los dedos, y de repente sientes que tu propia piel se te escapa, se te hace completamente extraña a lo que [la] llena por dentro. En el momento en que te das cuenta de que ya no eres capaz de verte, te das cuenta de que la imagen, en frente, no eres tú" - (Rauda, 2003, pp. 107-108).

En este aparte tengo la impresión de que Frida alude a lo que Parnas y Sass (2001) llaman fenómenos de descorporalización del self. Por momentos, por breves que estos sean, ella no estaba habitando su cuerpo. Veo esto factible por el ejercicio hiper-reflexivo sobre su propia percepción frente al espejo. Como sugieren Parnas y Sass (2001) en su modelo psicopatológico de la esquizofrenia a partir de una hiper-relfexividad inherente a este cuadro, la exposición de algunas de estas personas a mirarse al espejo por periodos prolongados facilita experiencias de despersonalización. Veo factible que este fue el caso de Frida, en quien la paulatina pérdida de translucidez corporal, asociada a jornadas extensas de soledad y autocontemplación reflexiva facilitó fenómenos de descorporalización de su self. En este sentido, encuentro muy sugestivas las siguientes palabras:

“Así que no rompí el espejo que tanto me torturó en un principio. Hubiese afectado a mi propia integridad. Y, Ilevando el análisis más lejos, no me limité a reflejar mi imagen cuando pintaba, sino que le uní la otra imagen, la realidad de mi cuerpo, rota, realmente. Le robé la imagen al espejo, a él que quiso usurpar mi identidad, a base de perseguirme, de ponerme siempre en entredicho." - (Rauda, 2003, p. 109).

Aunque es muy probable que, al principio, este tipo de experiencias hiperreflexivas hubiesen aparecido sin mayor control, veo muy probable que ella aprendiese a disponerse en un particular estado de conciencia creativa, tal como sugiere Mishara (2010b) sucedía con Kafka, quien aparentemente entraba en una suerte de estado de trance que Csikszentmihalyi (1990) denominó 'flow' (fluir) el cual pareciera facilitar un óptimo funcionamiento cognitivo durante periodos de creación. Una prueba de esto sería lo que escribió Kafka a Max Brod (citado en Mishara, 2010b. Pág. 6): "no es un estado de alerta, sino de olvido de uno mismo el requisito para escribir". Es además bien sabido -gracias a su diario- que Kafka se procuraba ese tipo de estados como parte de su proceso creativo, mediante periodos de privación de sueño y aislamiento (Mishara, 2012).

Veo muy probable que Frida hubiese recurrido a facilitar una experiencia similar como parte de su proceso creativo, pero a diferencia de lo que sucede con Kafka, no contamos con un relato claro que dé cuenta de ello. Lo único a lo que puedo recurrir es algunos fragmentos de sus cartas, citadas previamente, en donde alude a que mantenía periodos de insomnio frente al espejo" (i.e. "iEl espejo! Verdugo de mis días, de mis noches."), así como a la imagen de la (Imagen 5), donde se observa un ejercicio repetitivo, casi hipnótico si se me permite sugerirlo, en el que hace una clara alusión la sensación de sueño que la acompaña.

9 En sujetos que, por el motivo que fuese, terminan recluidos largos periodos de tiempo en cama presentan con mucha frecuencia problemas de insomnio, motivo por el cual suelen consultar a servicios médico para su manejo. (Stern, et al. 2010) 
No es más que una conjetura sin más base que mi intuición interpretativa clínica y fenomenológicamente situada; pero independientemente de que fuese mediante estados de conciencia alterados de manera voluntaria o no, no tengo dudas sobre el tipo de experiencias particulares que tuvo Frida mediante la reflexión intensa sobre su imagen especular como sustrato de su proceso creativo.

\section{Las dos Fridas}

De la mano con todo el marco de experiencias que -como he propuesto aquí-se surtieron en Frida como nicho de su particular tendencia a realizar autorretratos, quiero desarrollar un último punto: la probable presencia de fenómenos alucinatorios autoscópicos.

Epley y colaboradores (Epley, AKalis, Waytz, Cacioppo, 2008) sugieren que las personas que se sienten solas y que -por el motivo que fuese- carecen de un entorno social activo con el cual interactuar, tienden a atribuir características humanas a objetos no humanos. Esta

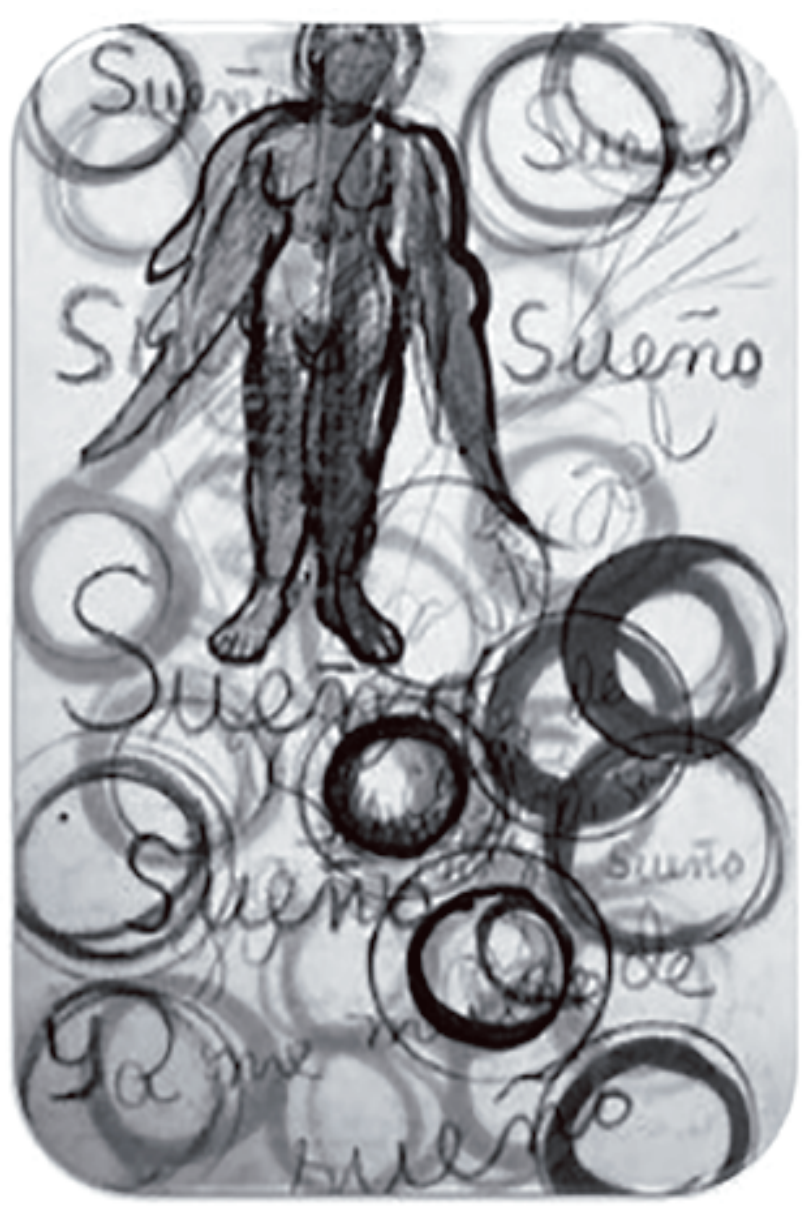
antropomorfización de estos objetos se da "mediante la invención de agentes cuasi humanos en su ambiente para que sirvan como potenciales fuentes de conexión" (Epley et al. p. 114. Traducción libre). Igualmente, ha sido descrito que aquellos sujetos privados de interacciones sociales por periodos largos (como náufragos o montañistas) reportan experiencias alucinatorias autoscópicas, especialmente las de tipo 4 (experiencias de presencia) (Mishara, 2010b). Según Mishara (2010b), diversos estados de privación social podrían asociarse con la sobre-excitación reactiva de ciertas redes cerebrales o módulos cognitivos relacionados con la interacción social, lo que podría explicar estas experiencias autoscópicas.

Como he insinuado a lo largo de este escrito, Frida estuvo sola en su habitación durante largos periodos de tiempo, lo que considero influyó fuertemente el espectro de experiencias de despersonalización descritos arriba. Encuentro muy probable, con base en los relatos y esquemas de su diario -así como su obra-, que Frida hubiese presentado francos fenómenos alucinatorios.

El primer elemento en el que baso esta apreciación es una composición de su diario titulado "ORIGEN DE LAS DOS FRIDAS. $=$ Recuerdo=". El texto versa sobre la descripción de un recuerdo de Frida cuando tenía cerca de seis años, momento en que "viví intensamente la amistad imaginaria con una niña... de mi misma edad más o menos". Al final de la entrada al diario anota "Asombrada de estar Sola con mi gran felicidad y el recuerdo tan vivo de la niña. Han pasado 34 años desde que viví esa amistad mágica y cada vez

Imagen 5. Foto Facsímil Diario de Frida Kahlo, 1995.

Jorge Guerrero. 
que la recuerdo se aviva y se acrecienta más y más dentro de mi mundo" (subrayados en el original). En el relato, Frida advierte sobre cómo recurría a esta 'amiga imaginaria', con quien compartía complejos juegos -aunque igualmente imaginados- como una manera de lidiar con su soledad ${ }^{10}$. Sin embargo, al leer la nota en el original se hace evidente que fue uno de esos textos editados por ella. La nota original, hecha en tinta azul, fue realizada 2 años antes (1948). En la edición de 1950 reescribe sobre el texto original, esta vez en tinta dorada oscura, cambiando -entre otros apartes- el original "sola con mi gran felicidad y el recuerdo de la niña" por "Sola con mi gran felicidad y el recuerdo tan vivo de la niña.". Es muy difícil saber qué quiso decir Frida con estos aparentemente sutiles cambios, pero no puedo dejar de fantasear -si se me permite una indelicadeza científica como esta- en que este vívido recuerdo, como lo definió, era hasta cierto punto una experiencia más compleja que una mera evocación mnémica; como si fuese un fenómeno al que pudiese recurrir con frecuencia ("Sola/recuerdo/la niña"). Esto me hace pensar que, aunque es bien conocido el cuadro de "Las Dos Fridas" (Imagen 6), las dos Fridas -del diario- apuntan a una experiencia más compleja y recurrente.

Imagen 6. Las Dos Fridas, 1939. Óleo sobre tela, 1,73 x 1,73cms Tomada de: $h t t p: / / w w w$. xromatadiakosmisi.com/a/fridakahlo

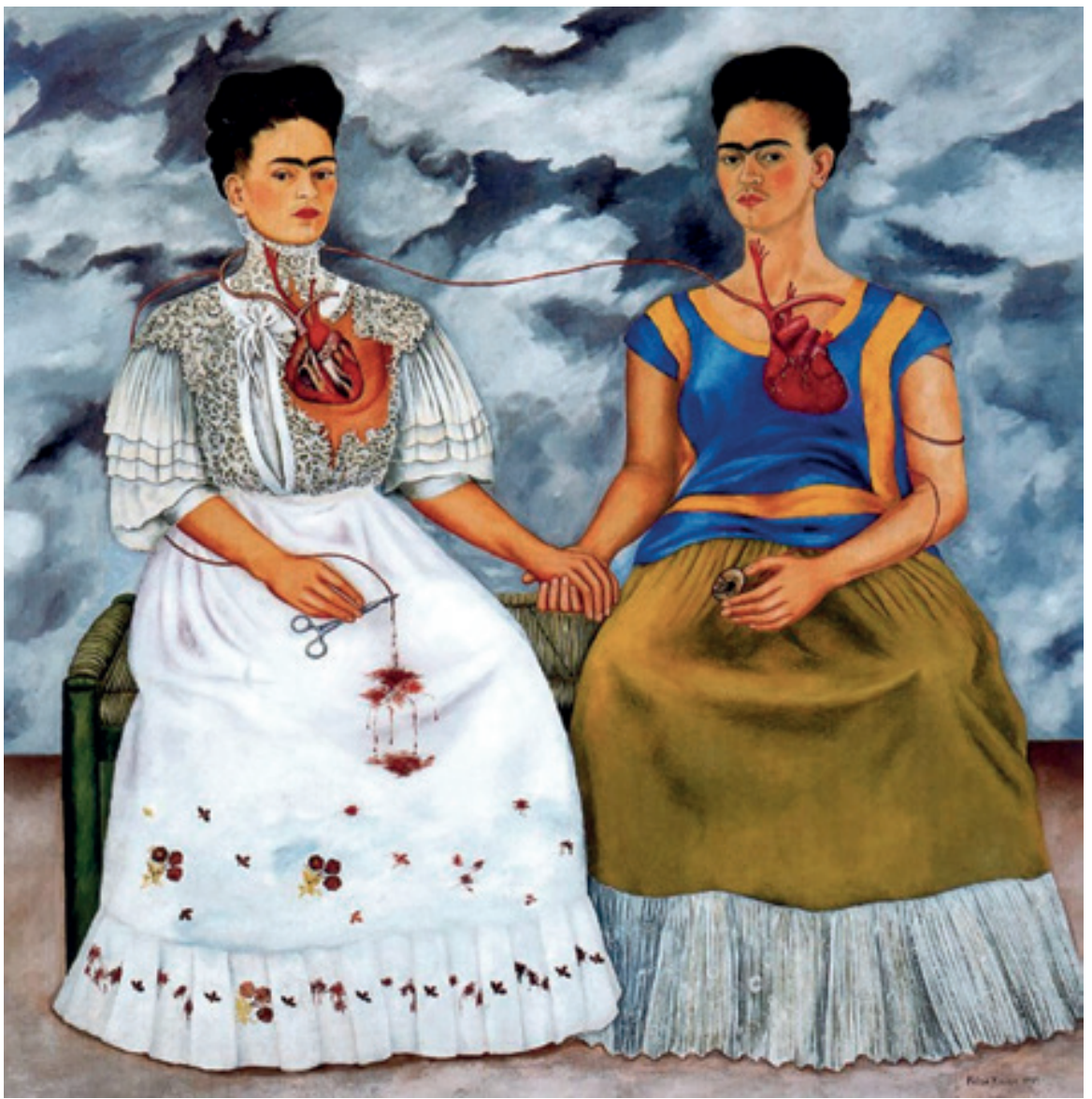

10 Durante su infancia Frida debió permanecer

en cama por largos periodos como consecuencia de la infección por poliomielitis que sufrió alrededor de los 6 años (Herrera, 1983). 
Tal como es sugerido por Inés Ruiz (2007) en su análisis de las ambivalencias y duplicaciones de su propia imagen, la representación de múltiples Fridas en la obra de esta artista no fueron hechos aislados. Todo lo contrario, las dos -y a veces más- Fridas aparecen en múltiples bosquejos y pinturas en diversos momentos de su vida. A continuación, algunos ejemplos (Imágenes 7, 8, 9, 10):

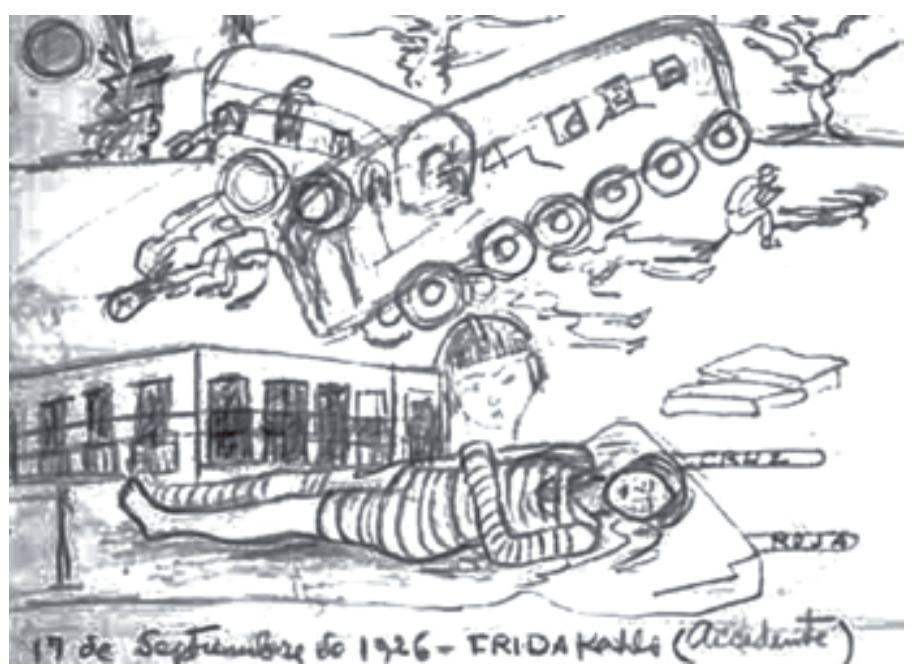

Imagen 7. Dibujo de su accidente en papel y lápiz. ¿1926? Tomada de: http://www.cronica.com.mx/ notas/2007/310882.html

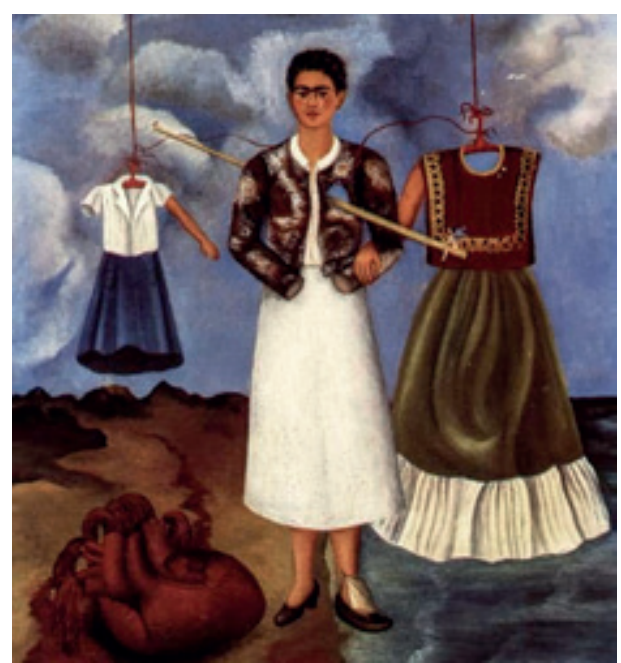

Imagen 8. Recuerdo o El Corazón, 1937. Óleo sobre tela, 40×28 cms Tomada de: https://bodegonconteclado. wordpress.com/2015/11/02/elogio-dela-muneca-las-anatomias-fantasticas-defrida-kahlo/

Como puede verse en la Imagen 7, hay un rostro de Frida que pareciera estar observando su propio cuerpo, como si fuese una espectadora desde la distancia. Este esquema fue realizado cerca de un año después del accidente según señala Ruiz (2007); si bien no se conocen comentarios al respecto de este dibujo por parte de la artista, encuentro esta ilustración muy sugestiva de un fenómeno autoscópico del tipo 3 (experiencias de estar fuera del cuerpo. Mishara, 2010 a) en la que pareciera representar la sensación de verse a sí misma desde una disociada distancia entre su Yo y su cuerpo herido. En la Imagen 8, por otro lado, se aprecian 3 imágenes, sugestivas de ser la misma Frida en tres momentos distintos: la primera, de izquierda a derecha, una Frida niña (¿de 6 años?), distante, de quien solo vemos un brazo intentando alcanzar la manga de la figura del centro, la cual es una Frida adulta sin manos y de quien pareciera pertenecer (por el agujero del pecho) el corazón tirado en el suelo a su lado. Finalmente, una Frida sin más cuerpo que la mano derecha entrecruzada con la Frida del centro. Es importante aclarar que, como sugiere Ruiz (2007), Frida solía representarse en su obra no solo con su rostro, sino con aquellos elementos con los que se representaba como 'el personaje que ella misma se encargó de construir'; así, por ejemplo, en Lo que el agua me dio (Imagen 3), Frida se representa a si misma por lo menos 4 veces: el vestido flotante en el agua, la mujer desnuda muerta (también en el agua), la mujer acostada sobre el regazo desnudo de la mujer indígena y, obviamente, sus pies sobresaliendo de la bañera. 


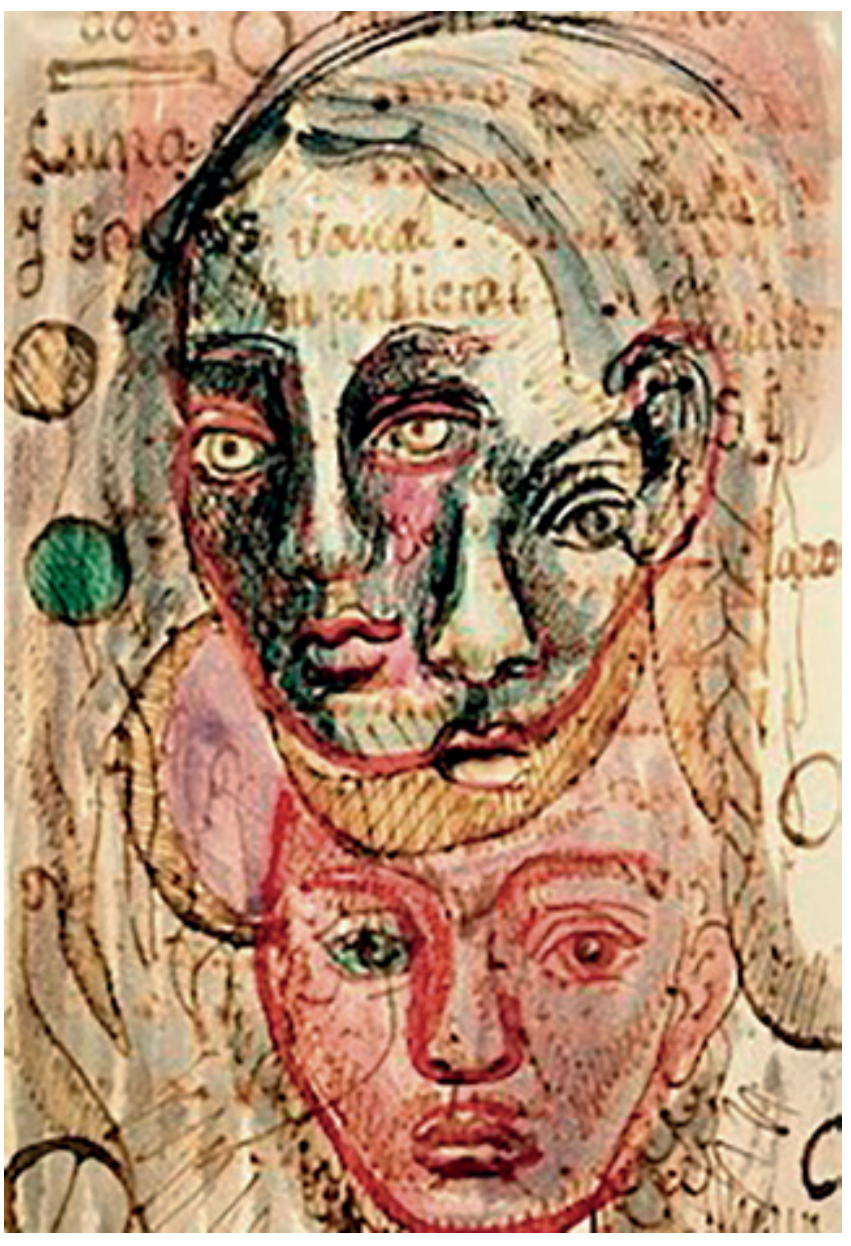

Imagen 9. Foto del facsímil del Diario de Frida Kahlo, 1995. Jorge Guerrero

Imagen 10. Foto del facsímil del Diario de Frida Kahlo, 1995. Jorge Guerrero
De manera más explícita, en las imágenes 9 y 10 podemos ver esquemas en su diario en los que es evidente una particular representación múltiple de sí misma. Creo que sus palabras -“Durante horas me sentía observada. Me veía. Frida dentro, Frida fuera, Frida en todas partes, Frida hasta el infinito" (Rauda, 2003, p. 107) - adquieren una nueva connotación a la luz de estas imágenes.

De igual manera, algunas de sus descripciones resultan sugestivas de más fenómenos autoscópicos, por ejemplo, cuando dice que "le robé la imagen al espejo, a él que quiso usurpar mi identidad, a base de perseguirme, de ponerme siempre en entredicho" (Rauda, 2003, p. 109), experiencia que semeja descripciones de alucinaciones autoscópicas tipo 2 (Mishara, 2010 b), aquellas en las que la mismidad del yo se ve alterada, como si compartiera su identidad misma. Estoy convencido que, con base en este tipo de experiencias sugeridas aquí, Frida tuvo la capacidad de plasmar en su obra no solo lo que imaginaba, sino lo que realmente experimentaba.

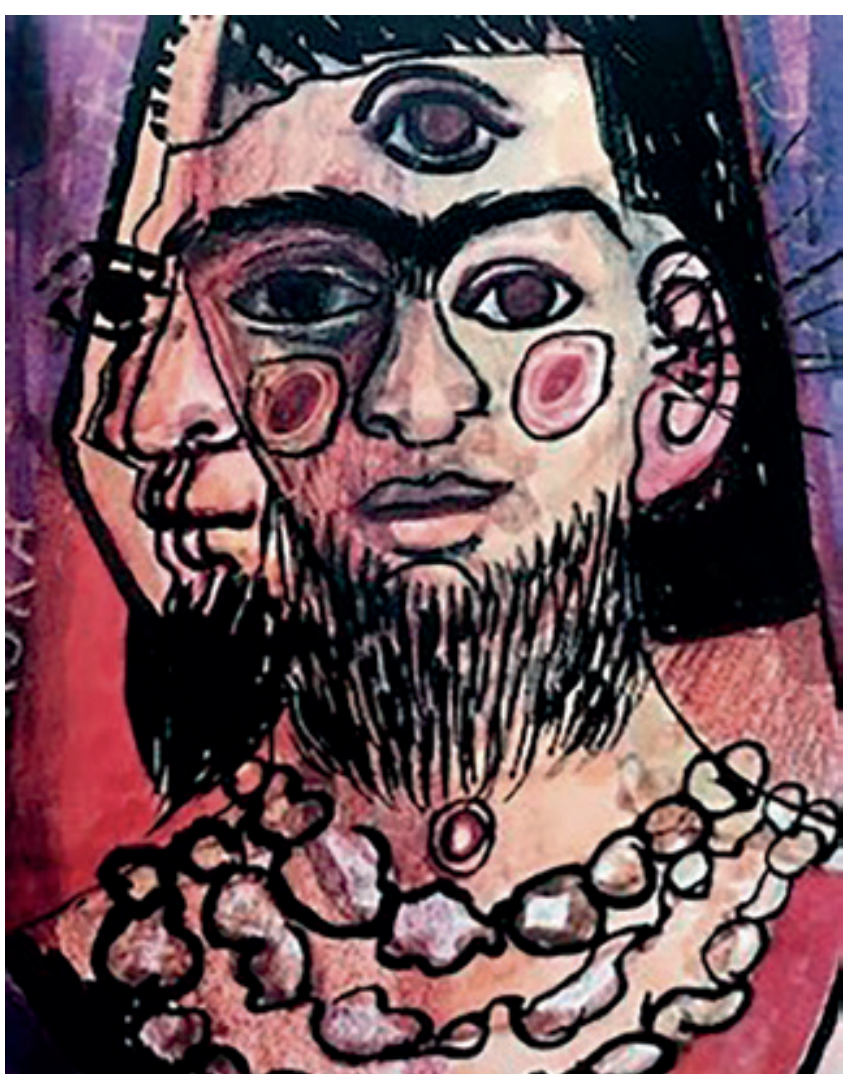




\section{Conclusión}

Es mucho lo que se ha dicho sobre Frida: Frida la mujer, Frida el personaje, Frida la artista; todo esto basado en interpretaciones surgidas de las más diversas claves de lectura de la obra y vida de esta extraordinaria mujer. El ejercicio que pretendí llevar a cabo aquí no es muy diferente, pero en esta ocasión procuré acercarme a las experiencias subjetivas que pudieron facilitar -y hasta cierto punto explicar- su creación artística.

Encuentro muy tentador decir que, a través de una lectura fenomenológica de su obra, es posible obtener información valiosa para el estudio de la mente misma. Veo en su obra no solo el dibujo de su imagen, si no de la experiencia de ser Frida. No obstante, jamás tendremos certeza sobre si las hipótesis que aventuro aquí sobre aparentes experiencias alucinatorias y de despersonalización fueron reales o no. Ella jamás podrá decirnos si logró elaborar un complejo sistema de representación hiperreflexiva de su propio cuerpo a partir del dolor y el sufrimiento; sin embargo, veo en esta lectura, fenomenológicamente situada, una oportunidad para acercarnos más a la intimidad que, creo, implica comprender su obra.

Frida fue el resultado de los eventos que marcaron su vida: una enfermedad congénita que facilitó lesiones en sus pies, las secuelas de una poliomielitis y un traumático accidente automovilístico, dolor crónico, exposición a jornadas largas de soledad frente al espejo, una gran inteligencia y capacidad imaginativa. Solo esta amalgama de coincidencias, pudieron dar luz a la artista Frida Kahlo quien, como ella lo afirmaba, no tuvo más elección que dibujarse a sí misma. 


\section{Referencias}

Budrys V. (2006). Neurological deficits in the life and work of Frida Kahlo. Eur Neurol; 55: pp: 4-10.

Csikszentmihalyi M. (1990). FLOW. The Psychology of Optimal Experience. Harper and Row. New York.

Damasio A. (1994). Descartes' Error. G.P. Putnam's Sons. New York.

Dosamantes, Irma. (2001). Self-Other representation and self healing through art. The Arts in Psychotherapy. 28: pp: 5-17.

Donahue, K.T. (2011). Frida Kahlo 1907-1954. En Encyclopedya of Creativity. Mark Runko, Steven Pritzker editores. Academic Press (EI Sevier copyright). London, UK.

Epley N., Akalis S., Waytz A., Cacioppo J. (2008). Creating social connection through inferential reproduction: Loneliness and perceived agency in gadgets, gods, and greyhounds. Psychological Science, 19: pp: 114-120.

Fierro M. (2013). Delirios, Cómo entenderlos. Editorial Kimpress. Bogotá.

Fuchs, Th. (2005). Corporealized and Disembodied Minds, a phenomenological view of the body in Melancholia and Schizophrenia. PPP, vol. 12 No. 2 (june): pp: 95-107.

Fuentes, C. (1995). Introducción. En Kahlo, 1995.

Gallagher, S. (2005). How the Body Shapes the Mind. Nueva York: Oxford University Press.

Garrido R. (2014). La Columna Rota 1944. Revista Médica Las Condes, volumen 25, número 4, julio. p. 717.

Guerrero A. (2012). Llanto, experiencias y narrativas: una aproximación antropológica a los trastornos depresivos en Bogotá. Tesis de maestría. Departamento Antropología Universidad de los Andes. Bogotá.

Herrera H. (1983). Frida. A Biography of Frida Kahlo. Harper and Row, New York.

Johnson, M. (2008). What makes a body? Journal of Speculative Phylosophy, New Series. Vol. 22, No. 3, Symposium II: Words, Body, War. pp: 159-169.

Kafka F. (1973). Letters to Felice. Stern J, Duckworth E. (Eds.). New York: Schocken Books.

Kahlo, Frida (1995), El diario de Frida Kahlo, un íntimo autorretrato. La Vaca Independiente S.A. (Ed.). México.

Kaufman D., Millstein M. (2013). Kaufman's Clinical Neurology for Psychiatrists, 7th edition. Elsevier Sounders. London, New York, Oxford, Sydney, Toronto, 2013.

Kettenmann A. (2003). Frida Kahlo. Köln, Taschen.

Leder, D. (1990). The Absent Body. Chicago University Press. Citado en Zarrilli Ph. (2004).

Stern T., Fricchioni G., Cassem N., Jellinek M., Rossenbaum J. (2010). Massachussets General Hospital Handbook of General Hospital Psychiatry. 6th Ed. Saunders (Elsevier). Boston, U.S.A.

Mishara, A. (2010, a). Autoscopy: Disrupted Self in Neuropsychiatric Disorders and Anomalous Conscious States. In D. Schmicking and S. Gallagher (eds.), Handbook of Phenomenology and Cognitive Science. Springer Science + Business Media B.V. 
Mishara, A. (2010, b). Kafka, paranoic doubles and the brain: hypnagogic vs. hyper-reflexive models of disrupted self in neuropsychiatric disorders and anomalous conscious states. Philosophy, Ethics, and Humanities in Medicine, 5:13.

Mishara A. (2012). The Literary Neuroscience of Kafka's Hypnagogic Hallucinations: How Literature Informs the Neuroscientific Study of Self and its Disorders. In The Cognition of Literature Edited by: Jaen-Portillo I., Simon J. U. of Texas Press. Austin (TX).

Parnas, J., and L. A. Sass. 2001. Solipsism, self, and schizophrenic delusions. Philosophy, Psychiatry, \& Psychology. 8, no. 2/3: pp: 101-120.

Plessner, H. 1981. Die Stufen des Organischen und der Mensch. Gesammelte Schriften IV. Frankfurt am Main: Suhrkamp. (Citado en Mishara, 2012).

Rauda J. (2003). Frida Kahlo, ed. Circe, Barcelona (12a impresión).

Ruiz I. (2007). Las Dos Fridas: lucha de contrarios, ambivalencias y duplicaciones en la obra de Frida Kahlo. Isla de Arriarán, XXX, diciembre. pp: 175-194.

Sadock B., Sadock V., Ruiz P. (2015). Kaplan \& Sadock's Synopsis of Psychiatry. Behavioral Sciences/ClinicalPsychiatry (11th Ed.). Philadelphia: Lippincott, Williams \& Wilkins.

Sanblom P (1999). Creativity and Disease, ed 12. New York, Boyras. New York, Boyars, 1999. En Budrys V. (2006). Ibidem.

Sass L. (2013). Varieties of Self Experience: A Comparative Phenomenology of Melancholia, Mania and Schizophrenia, Part I. Journal of Counsciousness Studies. 20 (7-8): pp: 103-130.

Zarrilli Ph. (2004). Toward a phenomenological model of the actor's embodied modes of experience. Theathre Journal. Vol. 56 No. 4 : pp: 653-666. 